\title{
AN EMPIRICAL INVESTIGATION ON HOW ANALYTIC NETWORK PROCESS GROUP DECISION MAKING INFLUENCES PROJECT RISK MANAGEMENT
}

\begin{abstract}
This paper is based on an empirical study of two interior design projects manager in a pair of quite similar (side by side) decoration projects. The purpose of this study is to develop an operative strategy for project risk management using Analytic Network Process. In this research we did an investigation on how group decision making influences managing risk in such a project. This was a rare occasion where the inputs, as opposed to the outputs, of the risk management process were examined. More problematically, the precise nature of the inputs does not seem to have been explored adequately in the previous researches. In this research, seven decision making models are designed for different phases of projects. The effect of dictatorial management approach and a group management approach on the risk management are compared. Comparison of the status of the projects run by the two decision making approaches showed significant differences between their cost and the duration.
\end{abstract}

Keywords: Analytic Network Process, Risk, Decoration project.

\section{Introduction}

The management of project risk is considered a key discipline by most organizations involved in projects. Best practice project risk management processes are claimed to be self-evidently correct. However, project risk management involves a choice between which information is utilized and which is deemed to be irrelevant and hence excluded. Project risk management, one of the main subjects of project management (Raz \& Michael, 2001), is the planning, organization, monitoring and control of all aspects of a project and it consists of risk identification, risk qualification, risk response development, and risk response control (Saynisch, 2005). Miller and Lessard (2001) pointed out that understanding and managing project risks in large engineering projects are challenging tasks at the early phase. In this research we done an investigation on how group decision making influences managing project risk. Decoration project risk has multiple sources including design, supply, process, transportation and sometimes choosing a contractor. Project management, faced with these risks, requires specific and adequate responses such as techniques, attitude and strategies for management of risk.

\section{Literature Review}

Vučijak , et al (2015) demonstrated the reliability of use of multi-criteria decision making tool for the purpose of selecting the best management scenario among different alternatives. The multi-criteria decision making tool enables decision makers to make informed decisions and achieve optimal results. Lin, et al (2015) concluded that with group decision making the likelihood and consequences of scenarios are described influence the perceived usefulness of a risk description. Tofan, et al (2016) evaluated how a newly proposed process (named GADGET) helps architects increase consensus when making group architectural decisions. The main purpose of our research was to use group decision making with Analytic Network Process (ANP) to control the risks for project success.

\section{Objectives}

The objective of our research was to investigate risk mitigation for two real projects using a suitable multi criteria decision making approach.

\section{Research Design/Methodology}

These two projects were a rare occasion where the inputs, as opposed to the outputs, of the risk management process were examined. More problematically, the precise nature of the inputs does not seem to have been explored adequately in previous researches. Two quite similar projects of the amphitheater decorations were selected as sample. Two the same equip the amphitheater halls projects were considered. Implementation of these two projects was the same map. Fixed price was the same for both contracts. The foundation funds intended for the implementation of both projects were identical. The researchers aimed to investigate the effect of management's approach. The effect of dictatorial management approach and a group management approach on the risk management compared. Process was divided into 7 phases. To decide in each 
phase a decision model based ANP method was used and the results was carried out. In the case of project A that was done with dictatorial management, decisions were made individually by the project manager. But in the case of project B that was done with group management decisions were made by a team management and conducted by a group of 8 experts.

\section{Data/Model Analysis}

In this research seven decision models were designed for different phases (Fig.1). Alternatives were selected based on individual judgments for the A project. As for the B project alternatives were selected based on geometric mean of group judgments. Both projects were implemented exactly according to the results. Finally, the difference in cost and time of the two projects were analyzed. One of the decisions models that related to the fourth phase of the project is shown as an example in Fig 2.

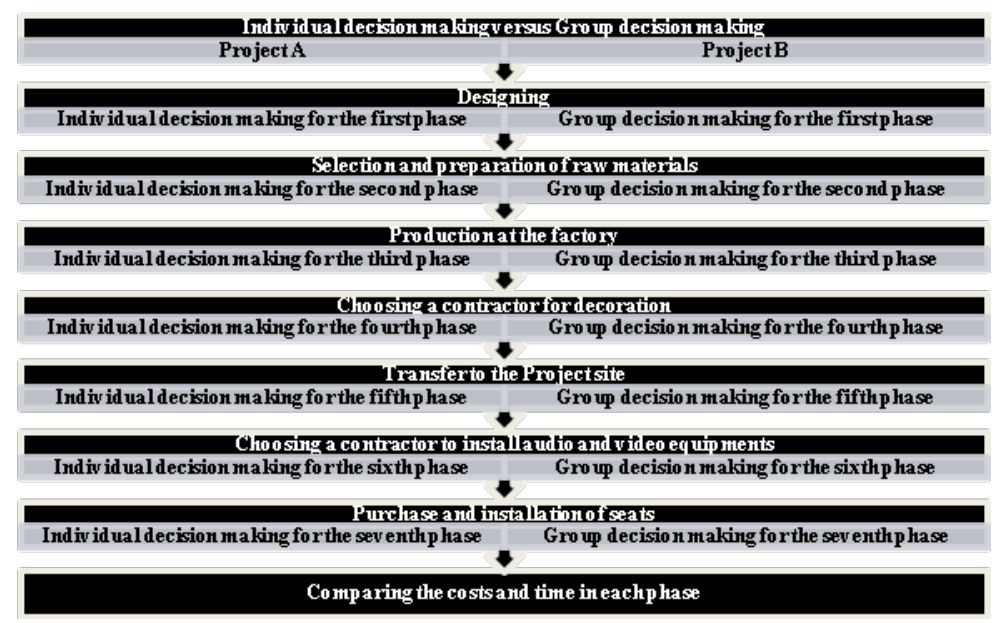

Fig1. Individual decision making versus Group decision making

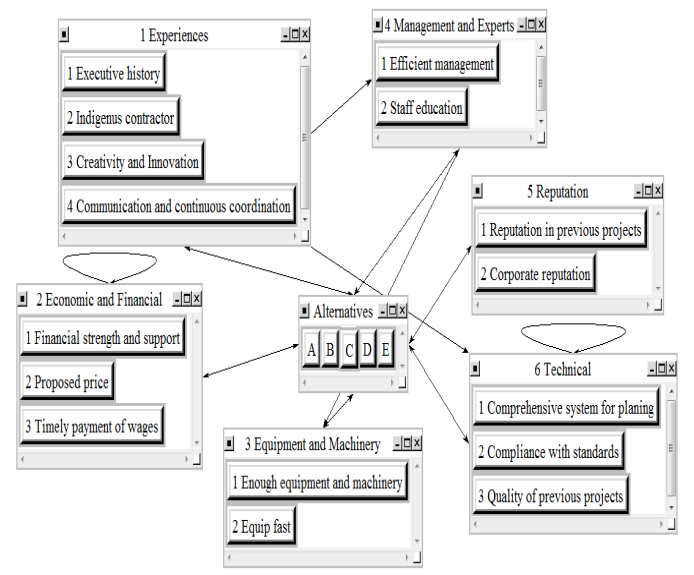

Fig 2. One of the decisions models related to the fourth phase

\section{Conclusions}

This paper is based on an empirical study of two decoration project managers in a pair of quite similar (side by side) projects. Comparison of the projects that have been implemented by individual decision making and projects that have been implemented by group decision making showed the difference between the cost and duration of the projects in the two states was significant. This means that the group decision making has been effective on decreasing of the managing project risk. According to researchers causes include: Lack of the necessary information to make a fully informed decision, emotion and impulse may take over, the decision may lack a balanced approach, the decision may be clouded by the subjectivity, prejudice and/or bias of the decision maker, through discussion, questioning, and collaboration, group members can identify more complete and robust solutions and recommendations.

\section{Key References}

Lin, L, Nilsson, A, Sjölin, J, Abrahamsson, M, Tehler, H. (2015). On the perceived usefulness of risk descriptions for decision-making in disaster risk management. Reliability Engineering \& System Safety, 142: 48-55.

Miller, R., \& Lessard, D. (2001). Understanding and managing risks in large engineering projects. International Journal of Project Management, 19(8), 437-443.

Raz, T., \& Michael, E. (2001). Use and benefits of tools for project risk management. International Journal of Project Management, 19(1), 9-17.

Saynisch, M. (2005). Beyond frontiers of traditional project management: The concept of project management second order (PM-2) as an approach of evolutionary management. World Futures, 61(8), 555-590.

Tofan, D, Galster, M, Lytra, L, Avgeriou, P, Zdun, U, Fouche, M, Boer, R, Solms,F. (2016). Empirical evaluation of a process to increase consensus in group architectural decision making. Information and Software Technology, 72: 31-47.

Vučijak, B, Midžić ,S, Silajdžić, I. (2015). Multicriteria decision making in selecting best solid waste management scenario: a municipal case study from Bosnia and Herzegovina. Journal of Cleaner Production, In Press, Corrected Proof, Available online. 